\title{
Exploring the Nigerian health system's response to female genital mutilation/cutting
}

Otibho Obianwu

Population Council

Follow this and additional works at: https://knowledgecommons.popcouncil.org/departments_sbsr-rh

Part of the Demography, Population, and Ecology Commons, Family, Life Course, and Society Commons, Gender and Sexuality Commons, International Public Health Commons, and the Sociology of Culture Commons How does access to this work benefit you? Let us know!

\section{Recommended Citation}

Obianwu, Otibho. 2018. "Exploring the Nigerian health system's response to female genital mutilation/ cutting," study brief. Abuja: Population Council. 
MAY 2018

\section{Lead Institution}

Population Council

\section{Key Partners}

Africa Coordination

Centre for

Abandonment of

Female Genital

Mutilation/Cutting,

Kenya

Global Research

and Advocacy

Group, Senegal

MannionDaniels

Ltd.

Population

Reference Bureau

University of

Washington (Prof.

Bettina Shell-

Duncan)

University of

California, San

Diego (Dr. Gerry

Mackie)

Funded by:

\section{Although Nigeria has shown}

a steady long-term decline in

female genital mutilation/cutting

(FGM/C) prevalence, the practice remains widespread. The health

system offers a good platform to

facilitate FGM/C abandonment

and provide care to survivors.

However, it is unclear if and how

the health system in Nigeria

implements existing FGM/C-

related policies, guidelines, and

laws.

\section{BACKGROUND}

Female genital mutilation/cutting is a culturally entrenched practice and form of abuse that violates the rights of women. ${ }^{1}$ It leads to negative health (physical, psychological, sexual), and social consequences, as well as poor health outcomes for mothers and children. Although Nigeria has shown a steady longterm decline in $\mathrm{FGM} / \mathrm{C}$ prevalence with a 58 percent decrease between the oldest cohort of women $(36 \%)$ and the youngest $(15 \%){ }^{2}$ the practice remains widespread. ${ }^{3}$ According to the 2013 Nigeria Demographic and Health Survey (NDHS), overall FGM/C prevalence in Nigeria was 25 percent among women ages 15 to 49 years, which means that approximately 9.8 million girls and women in this age group have been cut. ${ }^{3}$ These figures mask significant differences across Nigeria's sub-regions and ethnic groups with prevalence ranging from as low as 0.1 percent in Katsina state to 77 percent in Osun state. ${ }^{3}$

The health system offers a good platform to facilitate FGM/C abandonment and provide care to survivors. However, it is unclear if and how the health system in Nigeria implements existing FGM/C-related policies, guidelines, and laws. Little is known about the capacity of different cadres of health workers to implement FGM/C prevention and management activities or the existence of protocols, guidelines, policies, and training courses to guide such activities. The quality of care that women and girls receive when they present to a health facility with $\mathrm{FGM} / \mathrm{C}$ related complications also remains unclear.

\section{STUDY OBJECTIVES}

The Population Council's Evidence to End FGM/C research programme, in collaboration with the Federal Ministry of Health, will conduct a diagnostic assessment in order to:

1. Examine how the health care sector supports the prevention of FGM/C

2. Determine the role of the health care sector in the management of FGM/Crelated complications and the quality of care offered to clients

3. Identify possible solutions for strengthening the health care system's capacity to manage and prevent FGM/C

This study will use quantitative and qualitative methods to collect data in Imo state which was chosen due to its high prevalence of FGM/C (68\%) and medicalisation (61\%). ${ }^{3}$ The state was also a study site in a prior study on medicalisation conducted by the research programme and is one of the intervention states for the UNFPA - UNICEF Joint Programme on $\mathrm{FGM} / \mathrm{C}$. A similar study will be undertaken in Kenya and will allow for a comparison of health system responses across two different FGM/C contexts to build a regional evidence base to inform health systems interventions.

\section{HOW WE WILL COLLECT THE DATA}

\section{Structured consultative multi-stakeholder dialogues}

Information and perspectives on the current state of the health sector's response to FGM/C
The Population Council conducts research and delivers solutions that improve lives around the world. Big ideas supported by evidence: It's our model for global change. popcouncil.org

(C) 2018 The Population Council, Inc.

\section{POPULATION COUNCIL}

Ideas. Evidence. Impact.

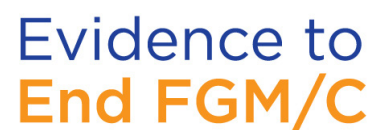

Research to Help Girls and Women Thrive

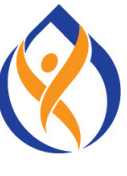


at both the national and state level will be gathered from a diverse group of 15 stakeholders involved in the FGM/C response and the health sector (e.g., health system administrators, health professional regulatory bodies and associations, FGM/C programme implementers, anti-FGM/C champions, and FGM/C focal persons at the State Ministry of Health and Women Affairs/Social Development). One dialogue each will be held with national and state level stakeholders respectively. Findings from this activity will also be utilised to determine the feasibility of study data collection activities and to revise them accordingly.

Key informant interviews of national/state level health system and FGM/C policy actors

Approximately ten different actors at both the national and state levels will be interviewed about their knowledge and views about the health system's policy process related to FGM/C prevention and management.

\section{Desk appraisal of FGM/C related law and policy documents}

A content analysis of FGM/C-related laws, policies, guidelines, and protocol documents will be conducted to determine whether their content sufficiently speaks to $\mathrm{FGM} / \mathrm{C}$ prevention and management in the health system, and outlines concrete steps for health system involvement in this area. The analysis will also examine the extent to which they facilitate or inhibit the health system's response to $\mathrm{FGM} / \mathrm{C}$ at state level.

\section{Focus group discussions and in-depth interviews with service providers}

Focus group discussions (FGDs) and in-depth interviews (IDIs) will be used to obtain service providers' (doctors, nurses, midwives, and community health workers) views about the implementation of FGM/C prevention and management services in the health system, and their feasibility and acceptability among service providers. Structured interviews will also be used to assess their knowledge, attitudes, and practices regarding FGM/C as well as their knowledge of existing FGM/C standards and guidelines. A total of nine FGDs and nine IDIs will be conducted.

\section{Multi-disciplinary clinical grand round}

A clinical grand round (a meeting in which health professionals discuss the clinical presentation, findings, and management of a patient's disease/health condition) will be held at the Imo State University Teaching Hospital, a tertiary health facility. This meeting will obtain information about the current management of $\mathrm{FGM} / \mathrm{C}$ complications among health workers. It will include the presentation and discussion of several clinical cases related to $\mathrm{FGM} / \mathrm{C}$ complications with different cadres of health workers and allied professionals like social workers and psychologists. Providers from the Federal Medical Centre, Owerri, will also be invited to attend.

\section{In-depth interviews with clients}

To verify the availability and content of $F G M / C$ services and determine client satisfaction with services received, IDIs
Figure 1: Sequence of data gathering activities

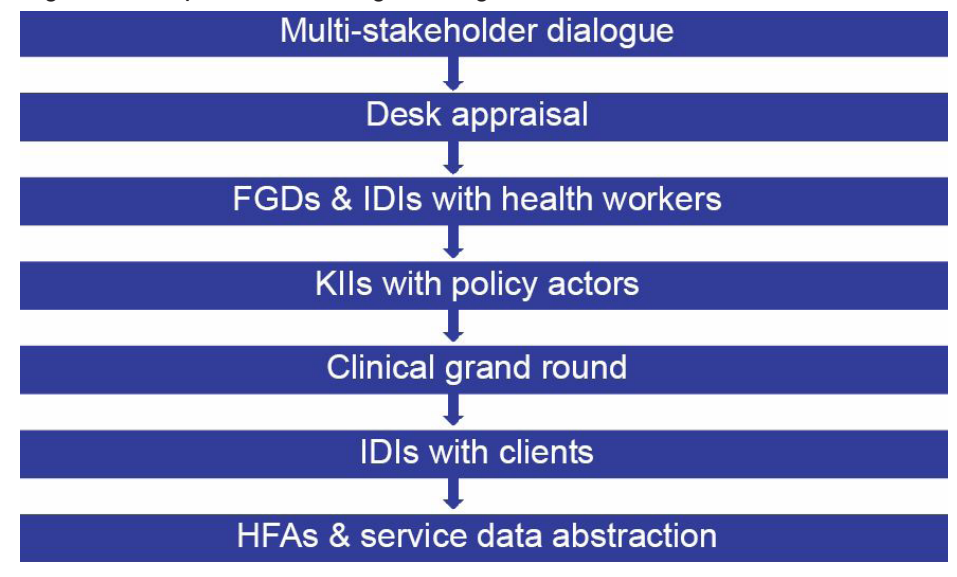

will be conducted among clients (i.e., women who have experienced complications of $\mathrm{FGM} / \mathrm{C}$ ). Researchers will also assess the perspectives and experiences of survivors' mothers/fathers (in cases where clients are girls) and their male partners. Approximately 18 interviews will be conducted.

\section{Health facility assessments and service data abstraction}

A systematic inventory/audit will be conducted at select tertiary (2), secondary (6), primary (42), and private (10) health facilities to ascertain their readiness to provide FGM/ $\mathrm{C}$-related services. The audit will assess the presence of necessary infrastructure, equipment, supplies, and human resources, as well as referral, provider supervision, and data management mechanisms. At ten of the selected health facilities, existing hospital registers, client record cards, and notes (at relevant service points) will be identified and reviewed and relevant service data abstracted.

\section{ANTICIPATED PRODUCTS}

Knowledge products such as study reports, policy briefs, peer-reviewed journal articles, and conference abstracts will be developed and disseminated widely. Study findings will also be shared with key actors at the national and state level. Findings are intended to inform programmes and policies to strengthen the preparedness of Nigerian health system actors (including health workers, health system administrators, health professional regulatory bodies, and health professional associations) to provide quality care to girls and women who have undergone FGM/C and to prevent new cutting of girls and women in health facilities and communities. Evidence generated could also be used by policymakers and programme implementers to design interventions preventing medicalisation.

\section{REFERENCES}

1. WHO. 2016. Female genital mutilation Factsheet 241. www.who.int/ mediacentre/factsheets/fs241/en

2. Shell-Duncan, B, R Naik, C Feldman-Jacobs. 2016. A state-of-the-art synthesis on female genital mutilation/cutting: What do we know now? Evidence to End FGM/C Programme Report. New York: Population Council

3. National Population Commission (NPC) [Nigeria] and ICF International. 2014. Nigeria Demographic and Health Survey 2013. Abuja, Nigeria and Rockville, Maryland, USA: NPC and ICF International. 